\title{
Meu corpo, minha vontade, minha dança
}

\author{
Daniele da Silva Faria \\ Mestranda PPGFIL - UFSCar
}

RESUMO: Tendo sido convidada a palestrar na quarta edição do colóquio "Para saber mais Schopenhauer", realizado na cidade de Campinas, São Paulo, Brasil, no corrente ano, elaborei uma breve comunicação, dado o limite de tempo, sobre o conceito de corpo na teoria metafísica de Schopenhauer. No entanto, no primeiro dia desse encontro, assistimos a duas conferências acerca da metafísica do belo, especificamente a respeito da hierarquia das artes e da metafísica da música. Depois da exposição de um dos palestrantes sobre essa hierarquia, foi aberto um tempo determinado para perguntas. Nesse tempo levantei a seguinte questão: onde se situa a dança na hierarquia schopenhaueriana? Muitos dos presentes arriscaram seus palpites, especularam, mas nenhum foi provedor de uma resposta satisfatória o bastante. Como havia dois dias até a data de minha conferência no encontro, resolvi pensar essa questão e arriscar minhas próprias conclusões, ainda que prematuras.

PALAVRAS-CHAVE: corpo; principium individuationis; dança.

ABSTRACT: I was invited to expose a paper on forth edition of "To know more Schopenhauer", a colloquium realized in Campinas city, São Paulo, Brazil, at this year. I have made one short paper, because of time, about the body's concept on Schopenhauer's metaphycal theory. But, at the first day of this meeting, we have seen two conferences about the metaphysic of beautiful, especifically about the hierarchy of arts and the metaphysic of music. After one's exposition about this hierarchy, it was open to make questions, and this time I asked: where's the dance on this schopenhauerian's hierarchy? A lot of the presents made their throbs, pondered, but no one was provider of one satisfactory response. How there was two days until my paper's date in this meeting, I resolved to think this question and to gamble my own conclusions, even if they are premature.

KEYWORDS: body; principium individuationis; dance.

O presente artigo é fruto de uma questão observada durante o colóquio Para saber mais Schopenhauer IV. Estou ciente que minhas ideias não estão totalmente amadurecidas, mas resolvi escrever e publicar esse artigo, com três intenções: 1) de praticar um exercício filosófico, submetendo minha interpretação do pensamento de Schopenhauer à crítica acadêmica; 2) de suscitar a dúvida nos especialistas e demais leitores da filosofia schopenhaueriana; e 3) de atualizar a hierarquia estética, introduzindo e conferindo à dança o estatuto filosófico de arte, ou seja, de representação independente do princípio de razão. Em que sentido atualizar a metafísica do belo de Schopenhauer? No sentido de resgatar essa teoria para dar conta de uma questão estética contemporânea já superada pelas belas artes, mas, ao menos ao que me pareceu, tem sido ignorada pelos filósofos em suas teorias sobre o belo, ou seja, permanece não problematizada, não teorizada filosoficamente. $\mathrm{O}$ 
problema é que apenas a metafísica do belo não me pareceu suficiente para dar conta de explicar esse fenômeno artístico em sua plenitude, quer dizer, enquanto objeto artístico sublime, completo, e em certo sentido, depende apenas de si mesmo para se situar como arte. O caminho que me pareceu mais firme para essa atualização da teoria metafísica do belo, e ao mesmo tempo superar filosoficamente essa questão é dado pela teoria metafísica da vontade, especificamente através do conceito de corpo. Esse me pareceu a chave, não apenas para resolver o enigma do universo, mas também para superar na filosofia essa modalidade artística, que despontou independente das demais belas artes apenas no século XX, trata-se da dança como manifestação artística em-si.

Tendo tratado no primeiro dos quatro livros de Die Welt als Wille und Vorstellung sobre epistemologia, no primeiro parágrafo do segundo livro dessa mesma obra, Schopenhauer afirmou que sua intenção era tratar das questões referentes à representação intuitiva, buscando "conhecer o seu conteúdo, suas determinações mais precisas e as figuras que exibem para nós".

Gänzlich also auf die anschauliche Vorstellung hingewiesen, werden wir verlangen, auch ihren Inhalt, ihre näheren Bestimmungen und die Gestalten, welche sie uns vorführt, kennen zu lernen ${ }^{1}$.

Nesse livro está em questão a metafísica da natureza, o mundo como vontade, especialmente o significado semântico e ontológico das nossas representações intuitivas. Mas o que seriam essas representações? Segundo o filósofo de Danzig, foram muitas as tentativas da filosofia, da matemática e da ciência da natureza de significá-las, mas, do seu ponto de vista, nenhuma delas conseguiu definir a constituição precisa dessas representações satisfatoriamente. Antes de prosseguir com a investigação schopenhaueriana, precisamos esclarecer para os leitores alguns aspectos importantes sobre sua teoria da representação.

A primeira frase do primeiro livro d' $\mathrm{O}$ Mundo é: "O mundo é minha representação" (Die Welt ist meine Vorstellung)², ou seja, o mundo como representação está colocado (Stellung) diante de (Vor) um sujeito que o intui intelectualmente. O

${ }^{1}$ SCHOPENHAUER, Arthur. Die Welt als Wille und Vorstellung (abrevia: WWV) - Sämtliche Werke (SW), I, $\S 17, p g$. 151. A respectiva tradução foi retirada de O Mundo Como Vontade e Como Representação. Tradução de Jair Lopes Barbosa. São Paulo: Editora UNESP, 2005, pg. 151.

${ }^{2}$ SCHOPENHAUER, A. $S W, I, \mathrm{pg} .31$. 
conhecimento do mundo como representação está submetido ao princípio de razão suficiente (Satz vom zureichenden Grund) que se divide em quatro modalidades ${ }^{3}$. Cada um desses princípios rege uma das duas classes de representações que podemos conhecer, sendo que ambas têm como fundamento a relação necessária entre sujeito e objeto. Todo objeto é algo que aparece, que está diante de um indivíduo, ou seja, um fenômeno; isso implica afirmar que representação é algo subordinado à formas cognitivas inatas a saber, espaço, tempo e causalidade, ou seja, à leis do princípio de individuação (principium individuationis) que proporcionam o entendimento, e pelas quais conhecemos todo o mundo empírico.

Existem duas classes de objetos distintas: as representações abstratas, cuja função de formar conceitos distinguem o homem dos demais animais, e as representações intuitivas, a saber, todo o mundo visível e as condições que o tornam possível. O universo é percepção intelectual de quem o representa, ou seja, um entrelaçamento de fenômenos e intuições empíricas válidas apenas enquanto referenciadas a um sujeito, e que não podem ser conhecidas sem esse, quer dizer, em-si, em seu estado puro, mas só possui realidade enquanto representado por um indivíduo, ou seja, determinado pelo princípio de individuação. Dessa forma, não pode haver objetos isolados, independentes, mas apenas objetos relacionados e dependentes de um sujeito que conhece tudo. Esse, por sua vez, também só existe mediante relação com o objeto, isto é, subordinado às mesmas leis que regem nossa intuição ${ }^{4}$ e entendimento ${ }^{5}$.

O mundo como representação, do ponto de vista do sujeito que o percebe, não passa de uma imagem intelectualmente entendida pelo sujeito - o entendimento é uma faculdade ativa, ele intui o mundo. Por exemplo, tudo o que nossos olhos vêem é luz refletida pelos objetos, ou seja, é energia capturada pelas córneas, acomodada e invertida pelo cristalino, formada na retina e transmitida eletricamente através do nervo ótico até a região cerebral responsável pela visão, no qual se processa o fenômeno de formação das imagens. Cada olho recebe e envia ao cérebro uma imagem, no entanto, vemos os objetos como um só, dada a capacidade cerebral de fusão dessas figuras. Sendo assim, tudo o que vemos são

\footnotetext{
${ }^{3}$ A saber, o princípio de razão do vir-a-ser, o princípio de razão do conhecer, o princípio de razão do ser e o princípio de razão do movimento.

${ }^{4}$ Entendamos intuição como objeto da primeira modalidade de representações (da mudança e do vir-a-ser).

${ }^{5}$ Nesse sentido, Schopenhauer torna intrínseca a dependência de sujeito e objeto - um só pode existir mediante referência ao outro.
} 
imagens representativas, mas o significado e o ser dessas imagens mesmas são totalmente diversos dessa energia refletida que percebemos. Investigar semântica e ontologicamente essas representações intuitivas está longe de ser uma tarefa simples, pois baseando-nos nas ciências, tudo o que conseguimos questionar e responder está, em última instância, expressado pelo princípio de razão ${ }^{6}$, ou causalidade que é a forma a priori fundamental do entendimento. A lei de causalidade (forma do princípio de razão que rege a primeira classe dos objetos possíveis para nossa faculdade de representação, ou seja, o mundo objetivo real) só nos fornece regras, ordenações sob as quais os fenômenos se manifestam como efeitos espaço-temporalmente, portanto só se aplica às representações, só existe condicionada a priori - quando o ponto de partida é o sujeito, ou a posteriori, quando o referencial é o objeto. Com base nas figuras do princípio de razão, apenas conectamos as representações numa série de efeitos e de causas, ou seja, numa série de fenômenos dispostos causalmente. Apenas respondemos o "como", o "quando", o "onde", o "por que", ou "para que", mas não o "que" das coisas, quer dizer, "que elas são em sua natureza mais íntima”, e "que elas significam”. Com base no princípio de razão, que nada exprime sobre a natureza das coisas e nada colabora para desvendar o significado desse mundo objetivo, não conseguimos descobrir o ser e as definições das representações intuitivas.

Schopenhauer pensou que o significado dessas representações é, de acordo com a própria essência delas, totalmente diferente dos fenômenos, de suas formas e leis mais gerais. Como então encontrar respostas para essa investigação se não através da razão?

Wir sehen schon hier, daß von außen dem Wesen der Dinge nimmermehr beizukommen ist: wie immer man auch forschen mag, so gewinnt man nichts, als Bilder und Namen. Man gleicht Einem, der um ein Schloß herumgeht, vergeblich einen Eingang suchend und einstweilen die Fassaden skitzirend. Und doch ist dies der Weg, den alle Philosophen vor mir gegangen sind ${ }^{7}$.

O filósofo deixa claro que através das leis do princípio de razão, ou seja, "de fora" não conseguiremos evidenciar o verdadeiro sentido (Bedeutung) do mundo, ou sua natureza

\footnotetext{
${ }^{6}$ Nihil est sine ratione cur potius sit, quam non sit - nada é sem uma razão pela qual é.

${ }^{7} \mathrm{SW}, \mathrm{I}, \S 17$, pg. 156. "Vemos, pois, que de fora jamais se chega à essência das coisas. Por mais que se investigue, obtêm-se tão-somente imagens e nomes. Assemelhamo-nos a alguém girando em torno de um castelo, debalde procurando sua entrada, e que de vez em quando desenha as fachadas. No entanto, este foi o caminho seguido por todos os filósofos que me antecederam”. MVR, I, §17, pg. 156.
} 
essencial. Apenas pelo contrário, i.e., “de dentro" é que encontramos o caminho para a resolução das questões propostas inicialmente:

Wir wollen die Bedeutung jener Vorstellung wissen: wir fragen, ob diese Welt nichts weiter, als Vorstellung sei; in welchem Falle sie wie ein wesenloser Traum, oder ein gespensterhaftes Luftgebilde, an uns vorüberziehen müßte, nicht unserer Beachtung werth; oder aber ob sie noch etwas Anderes, noch etwas außerdem ist, und was sodann dieses sei ${ }^{8}$.

Percebemos que essas questões se originam de uma suspeita, uma vez que para esse filósofo metafísico e materialista (embora pareça contraditório, do ponto de vista da filosofia schopenhaueriana, essas correntes não se opõem) tudo o que percebemos é energia que afeta nossa sensibilidade, na medida em que se manifesta no mundo, que é captada pelo nosso corpo e transmitida eletricamente ao nosso cérebro, que por sua vez, interpreta-a, deve haver um ser último, incondicionado, que a fundamente: "não há lótus sem caule"9 (Kein Lotus ohne Stängel) afirma um provérbio indiano citado nos Fragmentos para a história da filosofia ${ }^{10}$, i.e., não há mundo sem fundamento, não há fenômeno sem substrato. Assim, para conferir objetividade à primeira afirmação d'O Mundo, é necessário complementá-la com uma outra: Die Welt ist meine Wille ${ }^{11}$.

Schopenhauer acreditava que se fôssemos apenas puro sujeito cognoscente (rein erkennende Subjekt), ou como ele descreve metaforicamente "cabeça de anjo alada destituída de corpo" (geflügelter Engelskopf ohne Leib), jamais encontraríamos o significado do mundo ou sua transição (de representação para algo além disso). O puro sujeito do conhecimento é manifestado no mundo como indivíduo (Individuum), sendo o conhecimento - sustentação e condição do mundo como representação - intermediado pelo corpo, que nos enraíza no mundo, absorvendo toda a energia manifestada no universo, sentindo o mundo, percebendo-o e interpretando-o enquanto se mantiver vivo. $\mathrm{O}$ puro sujeito do conhecimento tem consciência do corpo como objeto intuitivo entre objetos, ou

\footnotetext{
${ }^{8} \mathrm{SW}, \mathrm{I}, \S 17$, pg. 156. “Queremos conhecer a significação dessas representações. Perguntamos se esse mundo não é nada além de representação, caso em que teria de desfilar diante de nós como um sonho inessencial ou um fantasma vaporoso, sem merecer nossa atenção. Ou ainda se é algo outro, que o complemente e qual sua natureza" MVR, $\$ 17$, pg. 155.

9 SCHOPENHAUER, A. Fragmentos para a História da Filosofia. Tradução Maria Lucia Cacciola. São Paulo: Iluminuras, 2003. Pg. 80. Curiosa citação proverbial que, do ponto de vista schopenhaueriano, coloca o mundo como lótus e a coisa-em-si como caule.

${ }^{10}$ Fragmente zur Geschichte der Philosophie, SW, IV, 475.

${ }^{11} \mathrm{SW}, \mathrm{I}, \S 1$, pg. 33. "O mundo é minha vontade".
} 
seja, como uma representação semelhante às demais, cujas mudanças são para ele ininteligíveis e alheias, mas além disso o puro sujeito cognoscente se relaciona com seu próprio corpo de uma maneira mais íntima, de modo que para ele o significado dos movimentos e ações do seu próprio corpo se revelam de uma outra forma que não aquela que define as atividades do mundo exterior, quer dizer, a lei de causalidade. De acordo com essa, o indivíduo nomearia "força", ou "qualidade", ou mesmo "caráter" a natureza das atividades e das exteriorizações de seu próprio corpo, mas segundo Schopenhauer, esses conceitos não esgotam o sentido da essência mais íntima e incompreensível das nossas ações e movimentos.

O filósofo afirmou que o sujeito consciente, que aparece como indivíduo, sabe, imediatamente, que a natureza e a significação dos movimentos do seu corpo, do seu atuar e do seu próprio ser é vontade. Se não fosse assim, o indivíduo perceberia seus movimentos como ele percebe a mudança (Veränderungen) dos fenômenos, segundo causas (Ursachen), estímulos (Reize) e motivos (Motive), a saber, como resultados estabelecidos por leis naturais. Mas o indivíduo conhece a influência dos motivos (Einfluß der Motive) não através de uma ligação entre manifestações fenomênicas com suas causas, mas diretamente, i.e., imediatamente, sem intermediação de terceiros, como a razão, por exemplo.

O sujeito cognoscente se identifica com seu próprio corpo de dois modos diversos: como fenômeno e como vontade. Com essa identidade, a metafísica de Schopenhauer se torna uma metafísica da natureza, pois confere ao corpo o status de via de acesso ao mais real do mundo, uma vez que o conhecimento que temos do nosso corpo não é um conhecimento discursivo (racional), mas sentido imediatamente, e esse sentimento nos fornece um tipo de representação intuitiva da coisa-em-si.

Dem Subjekt des Erkennens, welches durch seine Identität mit dem Leibe als Individuum auftritt, ist dieser Leib auf zwei ganz verschiedene Weisen gegeben: einmal als Vorstellung in verständiger Anschauung, als Objekt unter Objekten, und den Gesetzen dieser unterworfen; sodann aber auch zugleich auf eine ganz andere Weise, nämlich als jenes Jedem unmittelbar Bekannte, welches das Wort Wille bezeichnet ${ }^{12}$.

\footnotetext{
${ }^{12} \mathrm{SW}, \mathrm{I}, \S 18$, pg. 157. "Ao sujeito do conhecimento que entra em cena como indivíduo mediante sua identidade com o corpo, este corpo é dado de duas maneiras completamente diferentes: uma vez como representação na intuição do entendimento, como objeto entre objetos e submetido às leis destes; outra vez de maneira completamente outra, a saber, como aquilo conhecido imediatamente por cada um indicado pela palavra VONTADE”. MVR , §18, pg. 157.
} 
A metafísica da vontade se origina na experiência interna e externa, encontrando-se no "ponto certo" (rechter Punkt) que é o corpo. Como fonte de conhecimento, o corpo demonstra a especificidade da teoria do conhecimento no pensamento schopenhaueriano ${ }^{13}$, uma vez que segundo sua teoria, nosso corpo é para nós objeto da percepção e do pensamento, mas existe outra relação mais íntima que mantemos com ele, através de nossas ações e movimentos. Nesse ponto a experiência de mundo nos revela algo diferente: existe algo que está na raiz de nossa existência, algo interior, essencialmente volitivo e faminto que nos impele a desejar (não importa o quê) e a agir em busca de satisfação incessantemente. Esse aspecto desiderativo, Schopenhauer denominou vontade, que está presente em todos os entes da natureza. Essa palavra desvela a representação, o sentido, a essência, o fazer e os movimentos para o sujeito cognoscente, que deve sua individuação à uma identidade com o próprio corpo, que pode ser conhecido pelo sujeito de maneira direta e imediatamente, quer dizer, nosso próprio corpo é para nós um objeto imediato, ponto inicial do conhecimento do sujeito, desde que nós o conheçamos antes da aplicação das leis do princípio de razão.

Todo ser pode se relacionar com seu corpo através da vontade ou da razão, dependendo de quem é dominante, a necessidade de agir ou a consciência cognitiva - as duas relações revelariam dois aspectos de uma única entidade, como confirma Nussbaum:

Logo, embora não se possa perceber a vontade em si mesma, seria correto pensar que observar um corpo em movimento, especialmente movimento rápido, é um modo de entender algo sobre a natureza da vontade ${ }^{14}$.

Assim como o mundo, o corpo também pode ser interpretado como representação e vontade. Sendo representação ele é regido pelas leis do princípio de razão suficiente que regem todos os objetos fenomênicos. Por outro lado, corpo pode ser visto como o único

\footnotetext{
${ }^{13}$ A valorização do corpo é uma característica encontrada não só em sua teoria, mas também no pensamento budista e nos escritos de Nietzsche. Nesses três pensamentos pretende-se superar o dualismo cartesiano, a divisão entre res cogitans e res extensa.

14 "Thus, though one cannot exactly perceive the will in itself, it would be correct to think that watching a body in motion, especially rapid nimble motion, is a way of understanding something about the nature of the will". NUSSBAUM, Martha C. Nietzsche, Schopenhauer and Dionysus. Apud JANAWAY, C. (org.). The Cambridge Companion to Schopenhauer. Cambridge: University Press, pg 349.
} 
lugar no qual a vontade - enquanto essência - pode se expressar, podendo ser conhecida, em parte, através de suas ações:

Endlich ist die Erkenntniß, welche ich von meinem Willen habe, obwohl eine unmittelbare, doch von der meines Leibes nicht zu trennen. Ich erkenne meinen Willen nicht im Ganzen, nicht als Einheit, nicht vollkommen seinem Wesen nach, sondern ich erkenne ihn allein in seinen einzelnen Akten, also in der Zeit, welche die Form der Erscheinung meines Leibes, wie jedes Objekts ist: daher ist der Leib Bedingung der Erkenntniß meines Willens ${ }^{15}$.

O conhecimento da essência metafísica do mundo se dá através da experiência interna da mesma e o corpo, sendo uma manifestação singular da vontade, fruto de sua objetivação, deixa transparecê-la através de suas ações, que, no cerne, são as próprias ações da vontade. Essa descoberta capital se efetua no nosso próprio corpo enquanto representação, objeto entre objetos, realidade imediatamente conhecida do sujeito. Dessa forma, a metafísica da vontade se fundamenta no mundo da experiência possível, e Schopenhauer demonstra ainda mais sua inovação no que diz respeito ao modo de filosofar, situando o fundamento de sua própria metafísica na experiência do mundo e no auto-conhecimento, isto é, no conhecimento da vontade individual no fenômeno do corpo: "A metafísica da vontade elege o corpo como o ponto certo do entrelaçamento da experiência externa e interna, lugar onde o sujeito do conhecer e o sujeito do querer se identificam"16.

A identidade entre corpo e vontade não pode ser demonstrada, apenas evidenciada. Schopenhauer a denomina verdade filosófica (philosophische Wahrheit) por excelência $\left(\chi \alpha \tau^{\prime} \varepsilon \zeta o \chi \eta v\right)$, pois não é uma relação entre formas de representação (intuitiva e abstrata), mas entre representação intuitiva (corpo) e aquilo que está para além da representação, vontade $^{17}$.

\footnotetext{
${ }^{15} S W$, I, §18, pg. 159-160. "Por fim, o conhecimento que tenho da minha vontade, embora imediato, não se separa do conhecimento do meu corpo. Conheço minha vontade não no todo, como unidade, não perfeitamente conforme sua essência, mas só em seus atos isolados, portanto no tempo, que é a forma do fenômeno do meu corpo e de qualquer objeto. Por conseguinte, o corpo é condição de conhecimento da minha vontade". MVR, I, §18, pg. 159.

${ }^{16}$ RODRIGUES, E. V. F. Ética e teleologia na filosofia de Schopenhauer. Campinas, SP: [s.n.], 1999. Pg. 22.

${ }^{17}$ Não se trata de um conhecimento deduzível, científico, mas de outro tipo de conhecimento diferente do condicionado pelo princípio de razão, trata-se de um conhecimento imediato.
} 
...mein Leib und mein Wille sind Eines; - oder was ich als anschauliche Vorstellung meinen Leib nenne, nenne ich, sofern ich desselben auf eine ganz verschiedene, keiner andern zu vergleichende Weise mir bewußt bin, meinen Willen; - oder, mein Leib ist die Objektität meines Willens; oder, abgesehen davon, daß mein Leib meine Vorstellung ist, ist er nur noch mein Wille; u.s.w. $)^{18}$.

Conhecer a vontade como corpo significa conhecê-la como objeto, ou seja, ter consciência de objeto, mas não de si próprio, pois se o sujeito pudesse se tornar seu próprio objeto, ele deixaria de ser sujeito - subjekt e objekt nunca convergem na classe representacional, pois estão subordinados à lei de causalidade (que rege a primeira classe de objetos de conhecimento). Sua decifração depende de um outro tipo de classe representacional, que não opõe sujeito e objeto, a saber, a quarta classe de objetos, regida pela lei de motivação. Schopenhauer denominou o objeto dessa modalidade de "si próprio como querente" (das Selbst als Wollendes), i.e., como sujeito do querer. A consciência de si como sujeito do querer fornece ao indivíduo a percepção de si não como objeto entre outros, mas como a coisa mesma. Evidenciado, esse conhecimento duplo do corpo, como essência e como fazer efeito, torna-se pedra de toque para desvelar toda a essência da realidade na natureza. Por analogia, consideramos todos os demais objetos como nosso próprio corpo, ou seja, como representação, e como vontade, pois a essência do universo tende a se expressar indivisivelmente em todos os entes. Mesmo se manifestando nos atos de um corpo, não podemos conhecer a vontade completamente, isto é, não podemos conhecê-la em si, pois no momento em que, misteriosamente, manifesta-se no indivíduo, para poder conhecê-la, ele tem de submetê-la às formas dadas a priori na intuição, tempo e espaço, e à lei de causalidade.

Para Schopenhauer, a vontade aparece nos movimentos voluntários do corpo, pois é intrínseca a ele, ou seja, querer e agir são unos. Os movimentos do corpo são idênticos aos atos isolados da vontade, pois é impossível querer um ato sem, simultaneamente, percebê-lo como movimento corporal. Os atos da vontade e as ações do corpo não são conhecidos causalmente, mas são a mesma coisa, dada sob duas maneiras diversas:

\footnotetext{
${ }^{18} \mathrm{SW}, I, \S 18$, pg. 161. “...meu corpo e minha vontade são uma coisa só; ou, o que como representação intuitiva denomino meu corpo, por outro lado denomino minha vontade, visto que estou consciente dele de maneira completamente diferente, não comparável com nenhuma outra; ou, meu corpo é a OBJETIDADE da minha vontade; ou, abstraindo-se o fato de que meu corpo é minha representação, ele é apenas minha vontade, etc.” MVR, I, §18, pg. 160.
} 
imediatamente e intuitivamente, quer dizer, os atos da vontade aparecem objetivados (objektivierte), i.e., na intuição do entendimento, como ações dos corpos, e esses corpos, por sua vez, são a própria vontade objetivada (objektivierte). A unidade que existe entre o agir do corpo - ainda que ele seja precedido por motivos ou excitações involuntárias - e o agir da vontade torna a lei de causalidade, i.e., o princípio de razão, inútil, de certa forma, para desvendar a essência desses atos, dada de modo imediato ao sujeito consciente.

Der Willensakt und die Aktion des Leibes sind nicht zwei objektiv erkannte verschiedene Zustände, die das Band der Kausalität verknüpft, stehen nicht im Verhältniß der Ursache und Wirkung; sondern sie sind Eines und das Selbe, nur auf zwei gänzlich verschiedene Weisen gegeben: einmal ganz unmittelbar und einmal in der Anschauung für den Verstand. Die Aktion des Leibes ist nichts Anderes, als der objektivierte, d.h. in die Anschauung getretene Akt des Willens ${ }^{19}$.

Schopenhauer chamou corpo, no livro I, de objeto imediato (unmittelbare objekt) da vontade - se observado enquanto representação, e no livro II, do ponto de vista da coisa-em-si, denominou o corpo de "objektität des Willens". O termo "objektität" foi forjado por Schopenhauer para marcar o caráter insconsciente de imediatez do ato da vontade. Numa tentativa de manutenção dessa palavra na língua portuguesa, o tradutor Jair Lopes Barbosa verteu como “objetidade" e não como objetividade, pois segundo o tradutor, essa última não mantém o significado de "objektität". Nesse trabalho, adotaremos sua tradução para nos referir a esses objetos que são mais do que meros fenômenos; as objetidades são objetivações mais próximas da coisa-em-si. O corpo, bem como as Ideias platônicas, na teoria schopenhaueriana, é objetidade da vontade, pois seus atos são os próprios atos da vontade, i.e., agir e querer não se distinguem na atividade, apenas na razão.

Conforme pensamos um objeto desejado, distinguimos as ações do querer das ações do agir, mas no momento em que nossa decisão é executada, temos o autêntico ato da vontade, igual e imediatamente, quer dizer, sem a ponderação racional, manifestado na ação visível do corpo, dessa forma, efetivamente, são análogos os atos da vontade e os atos do

${ }^{19} \mathrm{SW}, \mathrm{I}, \S 18$ pg. 158. "O ato da vontade e a ação do corpo não são dois estados diferentes conhecidos objetivamente e vinculados pelo nexo da causalidade; nem se encontram na relação de causa e efeito; mas são uma única e mesma coisa, apenas dada de duas maneiras totalmente diferentes, uma vez imediatamente e outra na intuição do entendimento. A ação do corpo nada mais é senão o ato da vontade objetivado, isto é, que apareceu na intuição.” MVR, I, §18, pg. 157. 
corpo, e toda ação que recai sobre um, da mesma forma, simultânea e imediatamente recai sobre o outro.

A desconhecida coisa-em-si kantiana, para Schopenhauer, é o que nós intuímos imediatamente no fundo do nosso próprio ser como vontade, ou seja, é no agir do nosso próprio corpo, e dos demais (pois todos são manifestações do mesmo e indivisível substrato imanente universal) que a vontade se manifesta, e através desses atos podemos conhecer sua natureza, uma vez que o indivíduo no qual ela se manifesta é sujeito do conhecimento e sujeito do querer.

A finalidade do agir (ou do querer), para Schopenhauer, é alcançar algum tipo de prazer ou satisfação. Toda ação que recai sobre o corpo do indivíduo, recai igualmente sobre a vontade, desse modo "dor" é aquela ação sobre o corpo que o contraria, que contraria sua vontade, e prazer aquela que é conforme essa. Ainda que se manifeste na atividade corporal, não podemos absorver toda a unidade essencial, pois conheço a minha vontade que se expressa inteira e indivisivelmente em mim, essa mesma vontade se objetiva em cada ente, desde o reino mineral até o homem, mas se deixa entrever apenas através de suas ações. O conhecimento que temos dela é apenas em seus atos isolados, portanto temporalmente, e não se difere, mas depende do conhecimento do nosso corpo, esse é condição necessária para conhecê-la, mas não suficiente para compreendê-la em todos os seus aspectos, pois para que o indivíduo possa ter uma experiência de si mesmo como sujeito do querer, i.e., como objetidade da vontade, é necessário que ele tenha uma experiência afetiva e singular do seu próprio corpo, e para que essa seja possível, a razão não é necessária, mas sim a sensação do corpo como impulso de atração ou aversão.

A execução de uma resolução (Entschluss) da vontade se torna visível através dos movimentos corporais, que são fundamentados exteriormente por motivos, que delimitam o querer no plano individual, a saber, em um determinado tempo, em um lugar determinado, sob uma dada forma, mas os motivos não determinam o que $(d a \beta)$ se quer, o querer em geral, quer dizer, não cristalizam o impulso essencial numa dada direção. $O$ agir é fundamentado por motivos, mas nem por isso deixa de ser em-si essencialmente vontade. Motivos são razões, causas pelas quais a vontade se revela nos indivíduos, mas como a vontade noumênica está além do domínio das razões (domínio fenomênico), ela também não pode ser explicada através da lei da motivação, pois toda ação volitiva do corpo, ou 
seja, todo movimento é percebido como uma aparição fenomênica, e deixa transparecer o caráter do indivíduo que atua, i.e., a vontade mesma de cada indivíduo sob certos motivos. A execução dos atos da vontade se dá através de motivos sobre o caráter, que é uma regra universal e invariável na observação de certo conjunto de fenômenos. A condição dessa ação é o corpo como um todo, e cada ser vivo possui um caráter empírico que regula suas relações com os fenômenos naturais. Cada vontade particular é uma representação temporal, é um caráter empírico, determinado pela lei de motivação, que determina nossas escolhas e nossas ações. É precisamente o caráter que nos faz escolher isso e não aquilo. E quando nos perguntamos "por que escolhemos isso", a resposta só é possível no âmbito motivacional, não no metafísico, porque razões, causas, justificativas, estão no domínio do princípio de razão, enquanto o querer em-si não tem finalidade nem fundamento, o querer em geral é incondicionado, sem fundamento (Grundlos). O fato de um fenômeno fundamentar outro (motivos fundamentarem ações) não implica que sua essência não seja vontade. O fenômeno da vontade, ou seja, o corpo, relaciona-se totalmente com sua própria vontade, ou seja, com seu caráter inteligível, cuja aparição no tempo é seu caráter empírico. Dado o enfoque limitado espaço-temporalmente, não abordarei com profundidade a distinção entre esses caráteres. Basta fixarmos que cada movimento isolado pressupõe um caráter determinado e se segue de um motivo apresentado, cuja condição necessária é o corpo, que subsiste através e no fenômeno da vontade, i.e., no tornar-se visível da vontade, por isso é denominado objetidade da vontade.

O corpo animal e humano são adequações perfeitas da vontade animal e humana. Observando as partes de um organismo animal, percebemos que suas funções correspondem à mais apropriada (Angemessenheit) expressão da vontade na natureza. Cada órgão, sistema ou célula do corpo atua no sentido de manter o organismo objetivado na realidade, ou seja, atua buscando a manutenção da vida de sua espécie, por isso vontade é sempre vontade de vida (Wille zum Leben). As partes do nosso corpo que melhor correspondem à manifestação dessa vontade de vida são aquelas ligadas aos sistemas digestivo e reprodutor, pois alimentação é a base para manutenção da vida de cada indivíduo, mas como essa é finita, e a vontade de vida é infinita, a procriação é a forma de manter o indivíduo vivo através de seus descendentes, ou seja, uma forma de eternizar-se - 
para a vontade, o que importa é a objetivação da espécie, não de um ou outro indivíduo específico.

Zähne, Schlund und Darmkanal sind der objektivirte Hunger; die Genitalien der objektivirte Geschlechtstrieb; die greifenden Hände, die raschen Füße entsprechen dem schon mehr mittelbaren Streben des Willens, welches sie darstellen ${ }^{20}$.

Esse impulso que se manifesta a partir do fenômeno, ou seja, a vontade, não possui causa ou finalidade alguma, e o seu conhecimento se dá na totalidade do mundo intuído, que é o espelho no qual ela pode se ver refletida. Creio até aqui ter evidenciado que mesmo através do auto conhecimento não conhecemos a coisa-em-si em todas as suas modalidades, mas apenas como desejo de vida. Para que aprofundemos esse conhecimento, para que possamos compreender mais aspectos da coisa-em-si, é necessário que nosso conhecimento não esteja mais submetido aos limites do princípio de razão. E como não submetermos nosso conhecimento à razão? Como não situarmo-nos como sujeitos diante de um objeto? Para Schopenhauer a ascese e a contemplação estética tem esse poder de anular o sujeito. Através de elementos belos e sublimes da natureza, ou da obra de arte de um gênio, nossa mera consciência individual é elevada à condição de pura consciência, de espelho da vontade, que fornece não mais o conhecimento de figuras particulares, mas das próprias Ideias, sem nenhuma distorção, tal como elas são essencialmente - o conhecimento científico as distorce, pois apresenta o objeto de acordo com os interesses cognitivos. A arte, por outro lado, apresenta o objeto de modo desinteressado, ou seja, sem finalidade (zwecklose Zwechemässigkeit - finalidade sem fim), portanto o conhecimento que o artista genial proporciona não tem vínculo com a vontade, pois a subjetividade é anulada.

Para Schopenhauer, a completa filosofia deve ir além da física ( $\varphi v ́ \sigma ı)$. Por isso, nos dois primeiros livros do Mundo, ele analisou filosoficamente o conhecimento da representação e da vontade subordinado ao princípio de razão, e nos dois últimos livros (da metafísica do belo e da metafísica dos costumes), ele tratou da representação e da vontade, do ponto de vista desatado do princípio de razão suficiente. Tentarei, a partir de agora

\footnotetext{
${ }^{20} S W$, I, §20, pg. 168. "Dentes, esôfago, canal intestinal são a fome objetivada. Os genitais são impulso sexual objetivado; as mãos que agarram e os pés velozes já correspondem ao empenho mais indireto da vontade que eles expõem”. MVR, I, §20,pg. 167.
} 
situá-los brevemente da teoria estética schopenhaueriana da supressão do conhecimento relacional, e encaminharmo-nos para os dois últimos momentos dessa conferência.

Do ponto de vista individual, todo conhecimento adquirido é interessado e particular. Constituímos os objetos da realidade empírica apenas segundo o princípio de individuação. Para transcendermos o conhecimento dessas coisas particulares, é necessário que conheçamos a representação não submetida à razão, i.e., os arquétipos, as Ideias, únicas, eternas e imutáveis de Platão - para Schopenhauer é através delas que conhecemos a universalidade dos objetos particulares, pois elas se voltam para a objetidade dos objetos em geral. As Ideias platônicas, na teoria schopenhaueriana, são as únicas objetidades adequadas da vontade, pois não se submetem à individuação, mas proporcionam uma correspondência (Entsprechung) entre sujeito e objeto; elas compreendem nelas mesmas sujeito e objeto em perfeito equilíbrio:

Da wir nun also als Individuen keine andere Erkenntniß haben, als die dem Satz vom Grunde unterworfen ist, diese Form aber die Erkenntniß der Ideen ausschließt; so ist gewiß, daß wenn es möglich ist, daß wir uns von der Erkenntniß einzelner Dinge zu der der Ideen erheben, solches nur geschehen kann dadurch, daß im Subjekt eine Veränderung vorgeht, welche jenem großen Wechsel der ganzen Art des Objekts entsprechend und analog ist, und vermöge welcher das Subjekt, sofern es eine Idee erkennt, nicht mehr Individuum ist ${ }^{21}$.

Essa transição do sujeito do querer ao puro sujeito do conhecimento acontece antes de se ter acesso ao conhecimento das Ideias, libertando-o da condição individual, i.e., do sujeito do querer, cujo conhecimento é servil à vontade, tornando-o sujeito do conhecimento purificado, destituído de vontade, de conhecimento relacional, repousado e absorvido pelo objeto através de sua contemplação. Nessa experiência de "perder-se" na objetidade, tornamo-nos seu reflexo, desaparecem todas as relações, toda a multiplicidade, permanecendo apenas as próprias Ideias, o "que", na medida em que ele se apresenta nele mesmo, sem causa, i.e., incondicionado. Quando não há mais representação abstrata (conceitos), mas apenas a intuição do objeto sugando e preenchendo a consciência, o

${ }^{21} \mathrm{SW}, \mathrm{I}, \S 33$, pg. 254. "Visto que, como indivíduos, não temos nenhum outro conhecimento senão o submetido ao princípio de razão, forma que, entretanto, exclui o conhecimento das Ideias, então é certo: quando é possível nos elevarmos do conhecimento das coisas particulares para o conhecimento das Ideias, isso só pode ocorrer por meio de uma mudança prévia no sujeito (correspondente e análoga àquela grande mudança na natureza inteira do objeto) em virtude da qual o sujeito, na medida em que conhece a Ideia, não é mais indivíduo." MVR, I, §33, pg. 243. 
sujeito esquece de si próprio, dos seus desejos e sofrimento - é como se apenas o objeto existisse, e sujeito não houvesse mais. A consciência nesse caso, não é mais consciência de algo, mas do próprio arquétipo da coisa-em-si, da Ideia, que não pode ser apreendida por um indivíduo. Uma vez que se trata de um tipo de conhecimento metafísico, o estado de

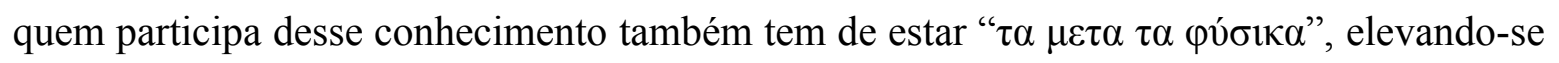
até a contemplação do universal no singular, o que antes era indivíduo se transforma em puro sujeito cognoscente, pura refração da vontade. Seu servo, o mero sujeito cognoscente, só conhece fenômenos particulares, determinados por ela, subordinados ao princípio de razão. Por sua vez, o puro sujeito do conhecimento e sua semelhante, a Ideia, estão além do princípio de razão; quem intui e quem é intuído não significam nada para esse puro sujeito, dado que quem intuiu foi abandonado naquilo que é intuído, ou seja, a consciência de quem intuiu a Ideia foi transformada na imagem mais nítida do objeto, transformada em seu semelhante.

A essência dos fenômenos, do puro sujeito que conhece e das Ideias é a mesma, i.e., vontade. A diferença está apenas no grau de objetivação que cada um manifesta dessa essência. Os fenômenos são objetivações imperfeitas da coisa-em-si, as Ideias são objetidades adequadas dela, mas essencialmente são idênticos. Quando suprimimos o conhecer relacional, quando levantamos o véu de maya, como diriam os hindus, que opõe sujeito e objeto, quando enxergamos o mundo além da representação, é o mesmo ímpeto cego que encontramos animando o universo todo. Nesse sentido, Schopenhauer conecta ontologicamente todo o cosmos: nós, e tudo o que percebemos como real ou imaginário, fazemos parte de um eterno elemento indivisível, ou seja, da vontade: Hae omnes creaturae in totum ego sum, et praeter me aliud ens non est ${ }^{22}$.

A ideia é um objeto da vontade-em-si, e tanto ela quanto vontade não se submetem às formas do nosso conhecimento, a saber, tempo, espaço e causalidade, que só se aplicam aos objetos fenomênicos - pois esses são múltiplos, nascem e perecem, ou seja, possuem características determinadas e passíveis de apreensão. A coisa-em-si, e as Ideias, por sua vez, escapam à essas formas de apreensão da realidade empírica, por isso, para que seja possível conhecer o essencial do mundo é exigido uma outra forma de sujeito, que implica em um outro modo de conhecimento: um sujeito puro, sem vontade.

\footnotetext{
${ }^{22}$ Upanixades. Tradução de A.H. Anquetil Duperon apud SW, I, §34. "Todas essas criaturas sou eu mesmo e exteriormente a mim não há outros seres”. MVR, I, §34,pg. 249.
} 
O indivíduo capaz de conhecer as objetidades da vontade, ou seja, capaz de conhecer e manifestar as Ideias, é expressado pela figura do gênio. Apenas essa rara manifestação fenomênica da vontade é capaz de ampliar seu horizonte de conhecimento para além dos limites da razão. O gênio suprime seu ego e apreende a universalidade dos objetos, que não são individuais, mas antes a essência nas Ideias que se lhe revelam como objetidades do universo, e é capaz de transmitir elas próprias em sua obra de arte. Ao observarmos uma obra enxergamos através dos olhos de seu autor, e ela é mais sublime, e nos traz mais satisfação, e por conseguinte, liberta-nos do sofrimento, na medida em que reproduz as Ideias com maior perfeição. Da personalidade genial todos temos um pouco, do contrário jamais seríamos capazes de contemplar a beleza e a majestade manifestadas na natureza, na vida ou numa obra de arte, mas cada indivíduo possui esse caráter genial num certo grau. Existem indivíduos mais geniais que outros, e conseqüentemente alguns são mais suscetíveis ao conhecimento das Ideias do que outros, ou seja, em alguns o arrebatamento é mais rápido, duradouro e profundo. Esse conhecimento estético é constituído de dois componentes inseparáveis, a saber, das Ideias platônicas e da consciência de si do indivíduo cognoscente não como sujeito do querer, pois todo querer é decorrido de uma carência, de um sofrimento, mas como puro sujeito do conhecimento exonerado de vontade, portanto não submetido ao princípio de razão. A beleza da vida e da arte nos arrebata, ainda que por instantes, de nossa condição subjetiva, sofredora, libertando-nos das tormentas das paixões e preocupações, do ímpeto do querer, e permite que tenhamos alguns breves momentos de serenidade, alívio e liberdade:

Denn in dem Augenblicke, wo wir, vom Wollen losgerissen, uns dem reinen willenlosen Erkennen hingegeben haben, sind wir gleichsam in eine andere Welt getreten, wo Alles, was unsern Willen bewegt und dadurch uns so heftig erschüttert, nicht mehr ist ${ }^{23}$.

O sentimento e o objeto sublimes são capazes de elevar o conhecimento do indivíduo, condicionado pela vontade, a um estágio superior de existência, um estágio puramente objetivo, representativo, no qual não há vontade, padecimento ou indivíduo.

${ }^{23} \mathrm{SW}$, I, §38, pg. 282. "Pois no instante em que, libertos do querer, entregamo-nos ao puro conhecimento destituído de vontade, como que entramos num outro mundo, onde tudo o que excita a nossa vontade, e assim, tão veementemente nos abala, não mais existe”. MVR, I, §38, pp. 268-269. 
Existem níveis de representatividade das Ideias nas belas artes que influenciam a capacidade de absorção do mero sujeito pelo objeto, e estabelecem uma hierarquia a partir das especificidades de cada uma delas: desde as mais materiais, no grau mais baixo, como a arquitetura e o paisagismo, gradativamente até as mais elevadas, a saber, as artes plásticas e a música - a bem da verdade, essa última possui uma posição especial nessa hierarquia. Quanto mais uma obra de arte expressar uma Ideia e arrebatar o indivíduo de maneira mais infalível, mais elevada ela é, e quanto menos ela depender da matéria para se manifestar como tal, tanto mais elevada ela se torna em relação às demais. A música supera as demais belas artes justamente porque é a menos material dentre todas - além de não ser representativa, quer dizer, não representar uma Ideia, mas a própria vontade em-si. Em sua hierarquia de modalidades artísticas, percebemos que Schopenhauer não incluiu uma, a saber, a dança. Por quê? Se ele tivesse incluído, que posição ela ocuparia? Sem dúvida, a seguinte parte é mais imatura do meu exercício filosófico até o momento, mas concluirei tentando responder essas questões com certa liberdade intelectual, tendo em vista, em certo sentido, atualizar a metafísica do belo schopenhaueriana e conferir à dança uma posição na hierarquia estética e o estatuto de bela arte.

A origem da palavra dança é incerta, mas o ato em-si não é difícil de supormos a origem. Com a licença dos médicos, antropólogos e historiadores, supomos um homem pré-histórico qualquer, no início da vida em sociedade: cheio de temores diante das forças desconhecidas e incontroláveis da natureza, o homem logo começou a se agrupar e a inventar deuses e rituais para dar graças e acalmar o ânimo furioso desses deuses. Nessas celebrações sempre havia algum tipo de música, manifestações físicas dos participantes, como gestos de oferenda, sacrifícios, comidas, bebidas - todas variantes de acordo com a divindade. As músicas quase sempre eram mais rítmicas e menos melodiosas. Talvez as músicas dos povos mais antigos sejam mais rítmicas do que harmoniosas porque desde os 3 meses de vida, um feto humano já tem desenvolvido seus órgãos auditivos, ele ouve e sente em seu próprio corpo os movimentos orgânicos e a voz da mãe de um lugar privilegiado: de dentro do próprio corpo dela. E se imaginarmos que o tronco humano é uma caixa de ressonância interna da voz, como as cordas do violão que ressoam dentro da caixa, mesmo estando acima e fora dela, o feto ouve com melhor nitidez, intensidade a voz da própria mãe antes de qualquer outra voz, e sente em seu próprio corpo a vibração provocada por ela 
e por seus demais movimentos. Recentes pesquisas feitas com bebês na fase pré-linguagem mostraram que eles reconheciam a voz da mãe, diante de muitas outras vozes femininas, mas a voz do pai, nem sempre era reconhecida. Mas são as batidas cardíacas de sua genitora que o feto ouve e sente dia e noite. Essa digressão é importante para ressaltarmos a origem intrínseca da percepção auditiva e dos movimentos do corpo, e como essas impressões nos afetam visceral e imediatamente, ao ponto de fazer com que inventemos objetos que imitem esses sons orgânicos para apaziguar nossa alma e nos trazer um pouco de satisfação estética.

Em culturas antigas, o ritmo fundamental, normalmente tocado em tambores, imita os batimentos cardíacos, como é o caso do ritmo nyabingui, do rastafarianismo. Existem outros povos que desenvolveram instrumentos musicais para imitar o canto das mulheres de sua tribo, como é o caso do djembê - instrumento criado pelos africanos da etnia malinké que povoam a costa centro-oeste africana. Em ambos esses povos, a dança está presente no ritual tanto quanto a música, ambas são inseparáveis, pois não haveria aquela dança se não

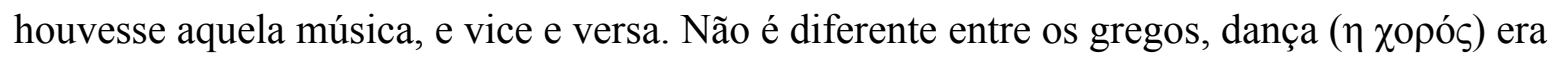
praticada em banquetes e ocasiões festivas; o coro ateniense, um grupo de dançarinos e cantores, dançava ao redor do altar de Dioniso, e dessa dança dionisíaca nasceu o drama ático, que primeiramente consistia em fábulas inseridas nos intervalos da dança ( $\varepsilon \pi \varepsilon 1 \sigma o ́ \delta ı)$, recitadas por um único ator. Musa $(\eta \mu \nu v \sigma \alpha)$ é o nome da deusa grega da música, da poesia, da dança, do drama e de todas as finas artes. É a partir do nome dela que derivam os termos

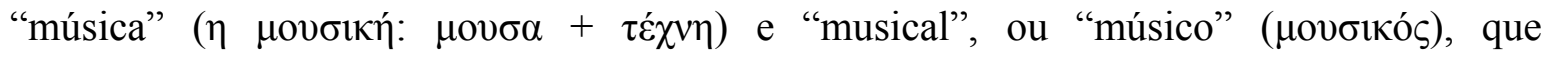
significavam qualquer arte regida pela musa, mas especialmente a música e a poesia lírica.

A música e a dança também estavam intrinsecamente conectadas para os gregos. $\mathrm{O}$ próprio Platão, em As leis, considerava a educação musical e a dança como meios para educar moralmente os cidadãos de sua pólis:

Todos os seres jovens são incapazes de ter em repouso seus corpos e suas vozes; eles buscam sem cessar remoer e falar, saltando e correndo, como se eles dançassem de prazer e brincassem entre eles, outros emitindo todos os sons de voz possíveis. Ora, os outros animais não têm noção de ordem e de desordem em seus movimentos, daquilo que chamamos de ritmo e harmonia, mas para nós, os deuses dos quais falamos, que nos 
foram dados para dividir as festas, esses mesmos deuses nos deram um senso de ritmo e de harmonia acompanhada de prazer $^{24}$.

Nessa obra, ele discutiu sobre as origens e a natureza da dança, bem como classificou coreografias e interligou estética à ética, prescrevendo a função das artes como educação moral, i.e., alcançar virtude. No livro sétimo, Platão situa a dança entre a ginástica e a música indicadas para todos os civis, no contexto da paidéia, palavra grega para educação, derivada como o verbo $\pi \alpha i \zeta \omega$ (dançar e tocar) da palavra $\pi \alpha \iota \varsigma$ (criança). E para que sua educação moral ficasse completa, havia mais um agente, o consumo de vinho em quantidade moderada nas festas: vinho, música e dança eram elementos chave para a instituição do simpósio grego, onde os jovens eram testados em habilidades de memorização poética, e onde eram encorajados a improvisar na música e na dança sob influência do álcool. Aqueles que não sabiam dançar eram os acoreutos, ou seja, não-educados, em última instância, um não-cidadão.

Passados quase dois mil anos desde Platão, até o século XIX o ballet clássico - cujo desenvolvimento de seu na França, com Luís XIV- era a única forma de dança considerada como arte. Mas a partir de então, bailarinos do mundo todo desenvolveram novas formas de expressão corporal desafiando os padrões vigentes, tais como: Isadora Duncan, ${ }^{25} \mathrm{Nijinski,}$ Mary Wigman, Martha Graham, Kazuo Ohno, Twyla Tharp, Merce Cunningham, Pina Bausch, Dimitris Papaioannou, Deborah Colker entre outros. Com os pés descalços, a dança moderna abandonou a ideia da arte como obra sacra, e deu seus primeiros passos com liberdade total de movimentos. Incorporando elementos diversos como o silêncio, a narrativa, o deslocamento do tempo e do espaço, o improviso e a repetição de movimentos, os dançarinos adquiriram liberdade para se expressar, criar e conquistaram seu estatuto de arte por excelência, tanto quanto a ópera ou a pintura.

Se for possível atualizarmos a metafísica do belo de Schopenhauer, inserindo essa modalidade, pensamos que ela deva se relacionar diretamente ao que expomos no início dessa conferência sobre o corpo como objetidade da vontade, pois a dança depende

\footnotetext{
${ }^{24}$ 653a. PLATON. Oeuvres Complètes. Tome XI (1a. parte). Paris: Les Belles Lettres, 1992.

${ }^{25}$ A pioneira do movimento, que revolucionou o figurino (baseado nos rituais dionisíacos), inovou também a estética do palco e o repertório musical, até então considerado adequado para a dança, e afirmou "O corpo do bailarino é simplesmente a manifestação iluminada de sua alma", "Tive três grandes mestres, os três grandes precursores da dança no novo século: Beethoven, Nietzsche e Wagner", "Sou inimiga do balé, o qual considero arte falsa e absurda que de fato está fora de todo âmbito da arte".
} 
diretamente do corpo do artista-intérprete, não necessariamente do coreógrafo que criou a obra, mas o corpo do bailarino é fundamental para expor sua obra de arte, que se manifesta em seu corpo na medida em que ele se movimenta sem finalidade alguma, apenas pelo prazer e absorção estéticos. O corpo como objeto intuitivo, é fonte de conhecimento causal, já o corpo como objetidade da vontade é fonte de conhecimento imediato, é através dos atos motivados do corpo que conhecemos os atos isolados da vontade, mas o que acontece quando esses movimentos do corpo não são motivados? Ou melhor dizendo: são motivados exclusivamente para si mesmos, têm como única meta a manifestação de uma Ideia? Os bailarinos contemporâneos buscam expressar não sentimentos particulares (um amor, uma raiva, uma angústia) mas sentimentos universais, em-si, O amor, A raiva, A angústia, O nada. Depois de tudo o que foi exposto, acreditamos que a dança deva possuir um lugar privilegiado na hierarquia estética de Schopenhauer, se não ao lado da música, ao menos imediatamente abaixo dela, pois a existência de uma pareceu-nos intrínseca a da outra. Muito ainda deveria ser aprofundado, mas encerro aqui essa conferência, com grande satisfação em poder contribuir para as pesquisas e discussões filosóficas do país.

\section{Referências bibliográficas}

SCHOPENHAUER, Arthur. Sämtliche Werke. Editadas e comentadas criticamente por Wolfgang Frhr. Von Löhneysen. Darmstadt, Wissenschaftliche Buchgesellschaft, 1974.

Iluminuras, 2003. . Fragmentos para a História da Filosofia. Tradução Maria Lucia Cacciola. São Paulo:

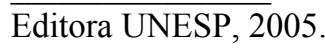

O Mundo Como Vontade e Como Representação. Trad. Jair Lopes Barboza. São Paulo:

JANAWAY, Christopher (org.). The Cambridge Companion to Schopenhauer. Cambridge: University Press.

PLATON. Oeuvres Complètes. Tome XI (1a. parte). Paris: Les belles lettres, 1992.

Recebido: $13 / 09 / 10$

Received: 09/13/10

Aprovado: 22/11/10

Approved: 11/22/10 